\title{
Sustained Neuromuscular Blockade after Vecuronium Use in a Premature Infant
}

\author{
Mitali Sahni, MD ${ }^{1} \quad$ C. Joan Richardson, $M^{1} \quad$ Sunil K. Jain, $M^{1}$ \\ ${ }^{1}$ Department of Pediatrics, University of Texas Medical Branch, \\ Galveston, Texas \\ Am J Perinatol Rep 2015;5:e121-e123.

\begin{abstract}
Address for correspondence Sunil K. Jain, MD, Division of Neonatology, University of Texas Medical Branch, 301 University Boulevard, 6.104 Waverley Smith Pavillion, Galveston TX 77555-0526
\end{abstract} \\ (e-mail: skjain@utmb.edu).
}

Abstract
Keywords
- neuromuscular block
- vecuronium
- aminoglycosides
- premature
- neonates

Background Prolonged use of neuromuscular blocking agents (NMBAs) is very common in critically ill children both in pediatric and neonatal intensive care units. There are no guidelines available for use of NMBAs in children or neonates in the US, and the data for their safety in this age group is limited.

Case Description Our case describes prolonged neuromuscular blockade following concurrent use of a NMBA along with aminoglycosides and steroids in the setting of renal failure in a premature infant.

Conclusion Prolonged use of NMBAs in preterm infants should be avoided if possible or should be restricted to the shortest possible duration and the smallest possible physiologically effective dose. Concurrent use of NMBAs with aminoglycoside and steroids should be avoided, especially in the setting of renal failure.
Prolonged use of neuromuscular blocking agents (NMBAs) is very common in critically ill children both in pediatric and neonatal intensive care units. The indications for their use include mechanical ventilation, pulmonary hypertension, tetanus, malignant hyperthermia, and occasionally after surgical repairs, such as tracheal reconstructions and anastomotic repairs. ${ }^{1}$ Although guidelines for use of NMBAs in adults have been present since 1995 , there are no guidelines available for NMBAs use in children and neonates in the United States. Hodges showed that neonates and infants require $45 \%$ less vecuronium than older children and adults. However in many nurseries, vecuronium is still administered using pediatric-dosing guidelines, which may be an overdose for neonates. ${ }^{2}$

In critically ill infants, use of NMBAs can lead to polyneuropathy or myopathy. ${ }^{3-5}$ Muscle denervation after the use of NMBAs may persist for several weeks after their use is discontinued, especially in patients with renal failure, hepatic failure, and metabolic acidosis ${ }^{3}$ which may be exaggerated with concomitant use of aminoglycosides. ${ }^{6}$ We present a case of a premature infant who developed persistent neuromuscular block (NMB), following prolonged administration of vecuronium bromide.

\section{Case}

A female infant of 28 weeks gestation was born via cesarean delivery for severe pregnancy-induced hypertension, premature prolonged rupture of membrane, class RF diabetes, and polyhydramnios. After receiving surfactant, she was extubated to continuous positive airway pressure. Treatment was begun with intravenous (IV) ampicillin (100 mg/kg every 12 hours) and IV gentamicin ( $5 \mathrm{mg} / \mathrm{kg}$ every 48 hours) for suspected clinical sepsis. She had an imperforate anus and type $\mathrm{C}$ tracheoesophageal fistula (TEF)/esophageal atresia with rectovestibular fistula. VATER syndrome was suspected so further evaluation was done which revealed an underdeveloped sacrum, echocardiography showed normal cardiac anatomy. Microarray sent showed normal female complement with two variants of unknown significance. The infant received

August 17, 2014 accepted after revision

February 25, 2015

published online

May 8, 2015
DOI http://dx.doi.org/

10.1055/s-0035-1549297. ISSN $2157-7005$.
Copyright $\odot 2015$ by Thieme Medical Publishers, Inc., 333 Seventh Avenue, New York, NY 10001, USA. Tel: +1(212) 584-4662.
License terms

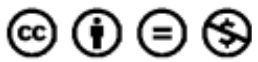


underwent primary repair of TEF, gastrostomy tube placement, and divided sigmoid colostomy on day 2 of life.

After surgery, the infant was placed on conventional mechanical ventilation, antibiotics were continued at the above-mentioned dosage, and pharmacological muscle paralysis was induced with vecuronium bromide infusion $(0.1 \mathrm{mg} / \mathrm{kg} / \mathrm{h})$ for 7 days to avoid agitation and TEF anastomotic site leak. On postoperative day 7 , urine output decreased significantly (day 7 of vecuronium infusion and day 9 of gentamicin). Initially lowdose dopamine $(5 \mu \mathrm{g} / \mathrm{kg} / \mathrm{min}$ ) along with IV hydrocortisone ( $0.25 \mathrm{mg} / \mathrm{kg}$ every 6 hours) was started. There was no improvement in urine output and later the patient developed anuria. She then received enteral metalazone $(0.4 \mathrm{mg} / \mathrm{kg}$ daily $)$ via gastrostomy tube and IV bumex $(0.01 \mathrm{mg} / \mathrm{kg}$ daily $)$ with no subsequent urine output for 12 days and with progressively increasing blood urea nitrogen (ranging from 94 to $126 \mathrm{mg} / \mathrm{dL}$ ) and creatinine (ranging from 3.3 to $5.74 \mathrm{mg} / \mathrm{dL}$ ). In addition she continued to have NMB even after discontinuing vecuronium. NMB could be transiently reversed with IV neostigmine $(0.05 \mathrm{mg} / \mathrm{kg})$ and IV atropine $(0.02 \mathrm{mg} / \mathrm{kg})$, which suggested that the NMB was due to vecuronium. This transient reversal was noted clinically as spontaneous movements, which stopped after the effect of these drugs wore off. The serum gentamicin levels (trough: $2.2 \mu \mathrm{g} / \mathrm{mL}$ and peak: $9.8 \mu \mathrm{g} / \mathrm{mL}$ ) were in the toxic range ( $\mathbf{- F i g . ~} \mathbf{1}$ ), hence gentamicin was discontinued. Peritoneal dialysis was not an option due to prematurity and the presence of a colostomy. Therefore, three single-volume exchange blood transfusions (80 $\mathrm{mL} / \mathrm{kg}$ ) were done to decrease the levels of vecuronium metabolite and gentamicin. There was no improvement in the renal failure and NMB. Magnesium levels started getting elevated with onset of renal failure, whereas the potassium levels were within the normal range.

Renal ultrasound was done at 2 weeks of life showed increased echogenicity of both kidneys consistent with renal injury and Doppler showed normal blood flow to both kidneys. All diuretics, steroids, and dopamine were continued till last day of life. Despite extensive efforts, acute renal failure progressed and could not be reversed. The patient died at 4 weeks of age due to multisystem organ failure.

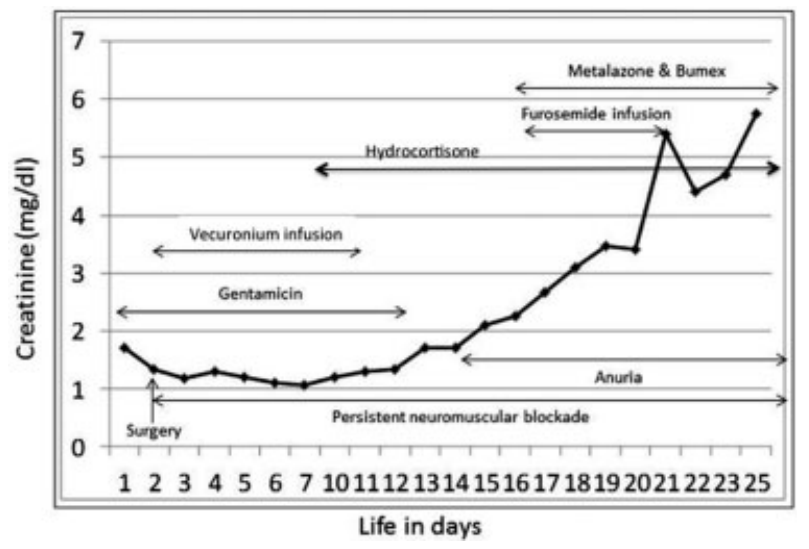

Fig. 1 Progressive renal failure with persistent neuromuscular blockade even after discontinuing vecuronium.

\section{Discussion}

This is the first reported case of a preterm infant with persistent NMB secondary to prolonged use of vecuronium infusion in the presence of renal failure. Our case highlights the importance of recognizing possibility of prolonged NMB with NMBAs in the presence of risk factors such as renal failure with concurrent use of aminoglycosides and steroids in preterm infants.

Commonly used NMBAs in neonatal intensive care units are pancuronium, vecuronium, rocuronium, and atracurium. Vecuronium is more commonly used because of its low incidence of cardiovascular side effects. It is mainly excreted via the hepatobiliary route but one of its metabolite 3desacetyl vecuronium is excreted via renal elimination. Hence, renal failure will decrease its excretion and prolong NMB. ${ }^{7}$

The precise etiology of prolonged and persistent NMB after discontinuing NMBA in critically ill patients is not well understood. It may be prolonged by drug overdose or by accumulation of active metabolites of NMBAs. The risk factors for prolonged and persistent NMB include renal failure, metabolic acidosis, use of aminoglycosides, and hypomagnesemia. ${ }^{4}$

Dupuis et al studied the interaction between aminoglycosides (gentamicin or tobramycin) and vecuronium prospectively in 16 patients ( 8 patients with therapeutic levels of aminoglycosides and 8 controls-who did not receive antibiotics). Duration of prolonged and persistent NMB along with recovery time were significantly longer in patients receiving aminoglycosides and vecuronium compared with those who received only vecuronium $(p<0.01$ for clinical duration and $p<0.0005$ for recovery). ${ }^{8}$ Segredo et al studied 16 critically ill adult patients receiving vecuronium for NMB. They found that persistent NMB after discontinuing vecuronium was associated with renal failure and high concentration of vecuronium metabolite (3desacetyl vecuronium) among other factors including metabolic acidosis, female sex, and high magnesium concentration. ${ }^{5}$ In adult studies, aminoglycosides such as gentamicin alone is known to cause NMB, which can be increased when used with vecuronium bromide. ${ }^{8,9}$ Inhibition of presynaptic acetylcholine release and stabilization of postjunctional membrane by aminoglycosides causes the prolonged NMB. ${ }^{10}$ The same phenomenon has not been described in preterm infants, and the safety of using gentamicin with vecuronium has not been established.

Vecuronium can lead to persistent NMB by two mechanisms. Both vecuronium and its metabolite (3-desacetyl vecuronium) are competitive antagonists of the acetylcholine receptor at the neuromuscular junction and block the action of acetylcholine, leading to muscle paralysis. ${ }^{11}$ In the presence of renal failure the excretion of 3-desacetyl vecuronium decreases, leading to prolonged NMB. Concurrent use of gentamicin with vecuronium will have a synergistic effect on NMB. Finally, steroids have the same structure as vecuronium, which may also lead to synergistic NMB action (-Fig. 2). ${ }^{12,13}$ 


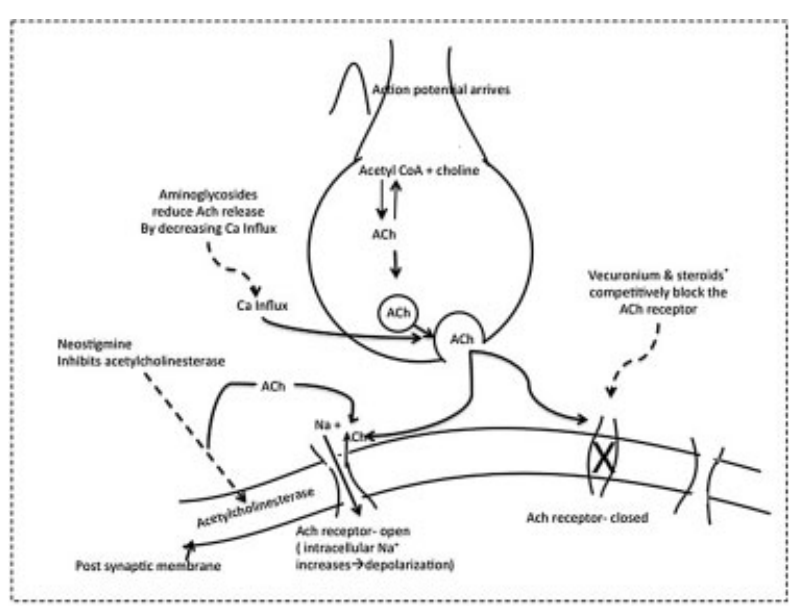

Fig. 2 Mechanism of action of various drugs acting on the nerve terminal. ${ }^{*}$, The mechanism of action of steroids in causing NMB is not well understood; $\rightarrow$, stimulating; $\rightarrow$ inhibiting.

In our case, we speculate that prolonged and persistent NMB was caused by prolonged use of vecuronium along with gentamicin and steroids in the setting of renal failure.

A limitation of the study is that 3-desacetyl vecuronium levels were not measured, and nerve stimulation studies were not done.

In summary use of NMBAs should be avoided if possible or should be restricted to the shortest possible duration and the smallest possible physiologically effective dose. Concurrent use of NMBAs with aminoglycoside and steroids should be avoided, especially in the setting of renal failure.

\section{References}

1 Playfor S, Jenkins I, Boyles C, et al; United Kingdom Paediatric Intensive Care Society Sedation, Analgesia and Neuromuscular Blockade Working Group. Consensus guidelines for sustained neuromuscular blockade in critically ill children. Paediatr Anaesth 2007;17(9):881-887

2 Hodges UM. Vecuronium infusion requirements in paediatric patients in intensive care units: the use of acceleromyography. Br J Anaesth 1996;76(1):23-28

3 Tabarki B, Coffiniéres A, Van Den Bergh P, Huault G, Landrieu P, Sébire G. Critical illness neuromuscular disease: clinical, electrophysiological, and prognostic aspects. Arch Dis Child 2002;86(2):103-107

4 Murray MJ, Brull SJ, Bolton CF. Brief review: Nondepolarizing neuromuscular blocking drugs and critical illness myopathy. Can J Anaesth 2006;53(11):1148-1156

5 Segredo V, Caldwell JE, Matthay MA, Sharma ML, Gruenke LD, Miller RD. Persistent paralysis in critically ill patients after longterm administration of vecuronium. N Engl J Med 1992;327(8): 524-528

6 Warner WA, Sanders E. Neuromuscular blockade associated with gentamicin therapy. JAMA 1971;215(7):1153-1154

7 Johnson PN, Miller J, Gormley AK. Continuous-infusion neuromuscular blocking agents in critically ill neonates and children. Pharmacotherapy 2011;31(6):609-620

8 Dupuis JY, Martin R, Tétrault J-P. Atracurium and vecuronium interaction with gentamicin and tobramycin. Can J Anaesth 1989; 36(4):407-411

9 Jedeikin R, Dolgunski E, Kaplan R, Hoffman S. Prolongation of neuromuscular blocking effect of vecuronium by antibiotics. Anaesthesia 1987;42(8):858-860

10 Sokoll MD, Gergis SD. Antibiotics and neuromuscular function. Anesthesiology 1981;55(2):148-159

11 Hibbs RE, Zambon AC. Agents acting at the neuromuscular junction and autonomic ganglia. In: Brunton LL, Chabner BA, Knollmann BC, eds. Goodman \& Gilman's The Pharmacological Basis of Therapeutics, 12e. New York, NY: Mc Graw-Hill; 2011:255-276: chap 11

12 Hirano M, Ott BR, Raps EC, et al. Acute quadriplegic myopathy: a complication of treatment with steroids, nondepolarizing blocking agents, or both. Neurology 1992;42(11):2082-2087

13 Dengler R, Rüdel R, Warelas J, Birnberger KL. Corticosteroids and neuromuscular transmission: electrophysiological investigation of the effects of prednisolone on normal and anticholinesterasetreated neuromuscular junction. Pflugers Arch 1979;380(2): 145-151 